\title{
Identifying and evaluating flexible approaches for automobile body production areas
}

\author{
Achim Kampker ${ }^{1}$; Georg Bergweiler ${ }^{1}$; Marian Bichler ${ }^{2}$; Jan Ole Hansen ${ }^{1}$; Tobias Christian Paulus ${ }^{1}$; Thomas Eser ${ }^{1}$ \\ ${ }^{1}$ Chair of Production Engineering of E-Mobility Components, RWTH Aachen University, Campus-Boulevard 30, 52074 Aachen, Germany \\ ${ }^{2}$ Dr. Ing. h.c. F. Porsche AG, Porscheplatz 1, 70435 Stuttgart, Germany
}

\begin{abstract}
The increasing variety of models with simultaneously lower and more volatile quantities in the demanding environment of automotive engineering calls for flexible production systems. Considering an automobile production process, the body shop can be characterized as particularly inflexible. This results from highly product-specific and automated technical solutions such as rigid fixture systems and grippers, commonly used to fulfil the demanding geometrical requirements of body parts and the respective production system. Therefore, several approaches have been developed to increase the body production flexibility. This paper presents a three-step methodology to identify promising flexibilization approaches for each area of body production, comparing the flexibility needs of the area with the flexibility offers of specific flexibilization approaches. The outcome of this methodology enables body production planners to derive in which flexibilization approaches to invest and which approaches to discard.
\end{abstract}

\section{Introduction}

Considering an external view [1] on automotive companies, the market sets the course: increasing product variety, shorter product life cycles, mass customization as well as the co-existence of combustion and electric engines driven by legislative regulations. [2, 3, 4]

Comparing this to the internal perspective [1] of the companies, their production systems have to meet the challenges set by the market. The existing conventional automotive production systems provide highly productdedicated solutions, particularly in the automobile body production. Demanding geometrical requirements, a high degree of automation to generate scale effects and the greatest vertical range of manufacture set the body shop to be the most inflexible automotive production sector and require high investment costs for the related equipment. [5, 6]

This generates an increasing need for flexible production systems that are able to cope with the product and production flexibility demanded by the market [7]. Therefore, the first focus of this paper is to analyze how this demanded flexibility can be characterized, summarized under the term flexibility needs. Looking at the flexibility enablers defined by HERNÁNDEZ [8] provides a clearer understanding how to reach this flexibility.

In recent times, many approaches to design production systems more flexible have been upcoming in literature and industry projects, offering more and more promising solutions [9]. Their potential to enhance the flexibility of production systems is referred to as flexibility offers.

A practical problem arises when companies and in particular specific body shop areas try to identify in which of all these approaches to further invest. To compare and prioritize these approaches, concepts to measure the flexibility potential of the available approaches are required. The conducted literature review of flexibility measurement concepts provided in this paper shows two theoretical deficits of the existing approaches regarding this requirement. First of all, there are currently no approaches linking the dedicated flexibility needs of specific areas to the flexibility offers of the approaches. Secondly, the existing approaches primarily measure flexibility in terms of economic values without connecting flexibility parameters to the final evaluation.

The methodology presented in this paper addresses the described shortcomings in theory and industry practice, proposing a three-step process to describe the flexibility needs of each body shop area, the flexibility offers of each approach and finally matching both to evaluate the potential to enhance flexibility of every area/approach-combination. Based on the theoretical concept of utility analysis and the application of graphical representation methods, a variety of sources of knowledge is connected to the flexibility enablers by HERNÁNDEZ to outline a stringent and visible decision process.

In a final step of this paper, the proposed methodology is implemented to analyze the flexibility 
potential of selected flexible approaches for an automobile body shop.

\section{Literature Review}

\subsection{Definition and Classification of Flexibility}

Flexibility plays an increasingly significant role for modern production systems, resulting in a variety of publications and industry projects introducing flexible approaches. Still a consistent understanding of flexibility has not been developed in existing literature in terms of manufacturing companies. [5] For this study, the definition according to WEMHÖNER is introduced as the basis for following investigations.

"Flexibility is the ability of a system to effectively adapt to different or changing, even insecure, requirements and constraints due to degrees of freedom." [5]

The classification of WIENDAHL shown in figure 1 differentiates the terms convertibility, reconfigurability, flexibility, changeability and agility, which are often used as synonyms in literature. The terms are classified in terms of their relevance for according product and production levels. [10]

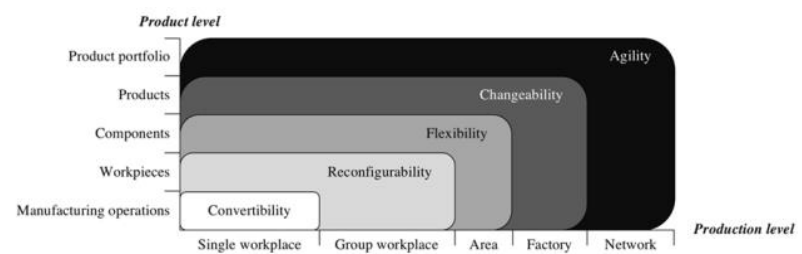

Figure 1. Change types according to WIENDAHL [10]

According to this classification, convertibility includes the dimensions manufacturing operations and single workplace. The term reconfigurability is used for workpieces and group workplaces. Flexibility describes the reaction of systems on a component level as well as an area level. Changeability is used for whole products and factories. Agility describes the characteristics of a system, which is able to adapt on a product portfolio level and a production network level. The superordinate change types include the respective subordinated types. Thus, flexibility includes the terms reconfigurability and convertibility and might be interpreted as being a part of mutability and agility.

Considering the term flexibility in a more detailed analysis, the classification shown in figure 2 is provided to better understand the dimensions of flexibility in the context of automotive companies.

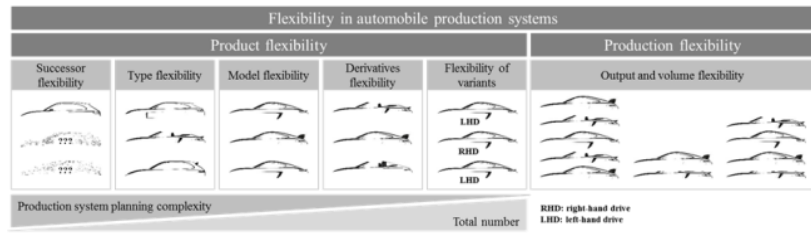

Figure 2. Relevant types of flexibility for the production of car bodies [11]
The term flexibility in the context of automobile production systems can be subdivided into the terms product flexibility and production flexibility.

In the framework of this paper, product flexibility describes the ability of a system to produce different products on a single production line. The generic term product is used as a collective name for the subcategories successor, type, model, derivative and variant according to LAMBERTZ. [12] A successor is defined as the subsequent generation of the actual product. The term type refers to the different shapes and sizes of vehicles, for instance limousines, sports cars or SUVs. They also very in the construction concept and materials used. A model is defined as a specification of a vehicle type, as most of the car manufacturers offer for instance different limousine models in various price categories. A derivative is defined as a design and performance specification within a model series (e.g. cabriolet, coupé or motorsport version). Variants usually differ in specific components or assemblies, whilst the structural concepts and materials used are generally identic.

It is particularly difficult to integrate a successor into the existing production line, as there is normally no information regarding the design and specification of the successor existing when the production line for the actual product is planned. Therefore, it becomes increasingly less complex to integrate new products into an existing production line, as there is more information regarding the new product is available and the integration effort decreases. Therefore, an integration of further variants usually does not require major changes.

Production flexibility describes to what extent the output quantity of all products (referred to as volume flexibility) and the quantity of individual products (referred to as output flexibility) manufactured within one production system can be varied, aiming to economically react on market demands. [13]

Having defined which types of flexibility modern production systems should achieve to stay competitive, it is important to analyze which factors influence the flexibility of a production system. Understanding them is crucial to develop approaches to increase product and production flexibility. Therefore, HERNÁNDEZ defined change enablers for production systems, which qualify the manufacturing equipment regarding its ability to react to changing conditions [8]. In the framework of body production, the relevant change enablers for this paper are modularity, scalability, mobility, integratability and universality, as it is shown in figure 3.

Standardized units and elements are summarized under the term modularity. Scalability includes the breathability of the production regarding technic, space and staff, which includes expandability and reducibility. The mobility of objects, such as robots on automated guided vehicles (AGV), describes to what extent operating equipment is moveable. Uniform software interfaces and connectivity in terms of material, information, media and energy are the subject of integratability or rather compatibility. The universality concerns the design and dimensioning of layout, technologies and products for different requirements. [15] 
Several concepts to enhance the flexibility of car body production systems have been developed in recent times. Component-integrated fixture-functions are one example for theoretical concepts described in according literature $[16,17]$. There are also existing industry projects to increase the body shop flexibility, for instance ComauFlex [18] and KUKA Matrix [19].

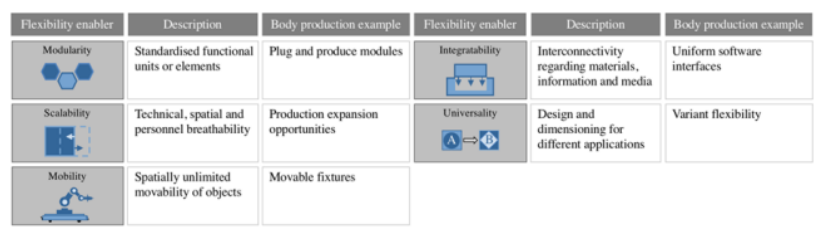

Figure 3. Flexibility enablers in car body production according to HERNÁNDEZ $[8,14]$ and complete as possible and include the country.

\subsection{Flexibility measurement in automobile body production}

When body production areas want to identify promising flexible approaches to enhance flexibility of their production systems flexibility, they try to assess the flexibility potential that stands behind certain approaches. To measure the amount of flexibility that approaches can generate, several approaches exist in literature applying different flexibility measurement methods to different areas of companies [20].

To measure the flexibility of production systems SCHUH ET AL. developed key performance indicators approach, which enables companies to evaluate flexibility in terms of output quantities, variants and product changes. [15] Through the collaborative research project VireS (virtual synchronization of product development and production system development) a simulation algorithm to determine the cost trend of production systems depending on output quantity and number of variants was developed. The simulation results are then analyzed to evaluate the respective flexibility. [21]

ROGALSKI developed a methodology to quantify the flexibility of production systems, focusing on economic aspects as the evaluation basis. A judgement of specific technical solutions and to what extent they influence flexibility is not a part of the methodology. [22]

Within the research of LAFOU ET AL. a methodology to evaluate the flexibility of production systems was developed. The methodology focuses on the importance of product-resources interfaces in flexibility assessment. Three so called flexibility inductors (gripping, setting and tooling interfaces) were identified. The flexibility is measured using the variable synergy (which itself is the quotient of the total number of components with interfaces and the total number of interfaces), comparing the synergy value after and before the integration of a new product. [20]

WEMHÖNER presented a methodology to construct a framework with appropriate instruments to plan for and optimize flexibility for an automobile body shop. The need to measure flexibility is integrated into a larger assessment model, using cost reduction, increase of profitability, minimizing undercapacity and reduction of risks as target criteria for flexibility. [5]

LAMBERTZ introduced a flexible approach for an automobile body production called FlexCell. In the framework of this approach, LAMBERTZ developed a methodology to assess the flexibilization potential of specific modules, selecting accessibility, approachability, collision safety, investment cost, running costs, reconfiguration costs and logistics costs as the target criteria. [12]

Summarizing this literature review, it could be stated that there are many concepts in literature to measure the flexibility offers of certain approaches, but there has not been an attempt to link the flexibility needs of different production systems' areas to the flexibility offers of the approaches yet. As many companies want to increase their body production systems' flexibility and know that there are many approaches on the market, but at the same time they are not able to select which ones to invest in, a practical deficit can be identified here.

Furthermore, a deficit in theory is observable when considering the approaches developed especially for the automobile body shop. They merely take economic parameters for their assessment and neglect the importance of key flexibility figures such as the flexibility enablers proposed by HERNÁNDEZ and the specific body shop requirements in terms of flexibility.

\section{FIGURES AND TABLES}

Based on the identified theoretical and practical deficit of the described flexibility concepts in terms of selecting approaches for automobile body production, the following part presents a methodology linking the flexibility needs of each body production area to the flexibility offers of specific flexible approaches. The first chapter introduces the theoretical concept of the methodology, an implementation based on industry examples is provided in chapter 3.2.

\subsection{Description of process steps}

The methodology is based on a three-step process as it is shown in figure 4 . The required input information is the definition of specific body production areas and available flexible approaches to analyse. As not every car manufacturer / supplier encompasses all existing body production process steps and also does not have the access to all available flexible approaches existing on the market / in theory, this step is already crucial to reduce the amount of work to be done to an efficient level. Furthermore, expert knowledge and a set of scientific and company-internal and -external sources are required to assess the different approaches. The output of the methodology is a ranking per area, showing which approach is the most promising for the specific flexibility requirements of the area. The ranking enables body production planners to identify in which flexible approach to further invest. 


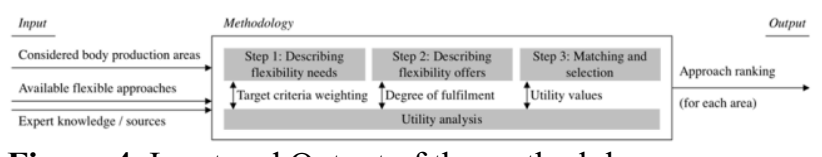

Figure 4. Input and Output of the methodology

The three steps of the methodology were designed similar to the theoretical concept of a utility analysis, whilst each step represents one part of the procedure of a utility analysis. The final ranking is generated comparing the utility values of each area-/approach-combination. In the first step of the methodology, the flexibility needs of each area are analysed. In the context of the utility analysis, this step aims to describe the preferences of the decision maker respectively the target system. This target system to categorise the flexibility needs is designed according to the above-mentioned theory of change enablers for production systems developed by HERNÁNDEZ [8]. The evaluation criteria are therefore scalability, universality, mobility, integratability and modularity. Having defined the body production areas to be analysed (input information), experts for each production area need to be appointed. Their expert knowledge is set to be the basis of evaluation. Expert interviews are conducted in which the experts rate the significance of each flexibility enabler for the specific area in comparison to the other enablers. This is modelled using a pairwise comparison method, as shown in figure 5. A rating of 1 expresses that two enablers have the same significance, a rating of 2 implies a higher and a rating of 0 a lower significance of each enabler compared to the other enabler. The result is displayed using a matrix structure and summing up the line entries.

In order to get a meaningful rating, the outcome of several expert interviews is summarised calculating an average result for each flexibility enabler. The results are then weighted according to their proportionate significance and the result is shown as a percentage share. Subsequently, we can identify very easily which flexibility enabler is the most significant for a specific body production area. In an example, shown in chapter 3.2 , the universality criterion is the most significant. These percentage shares as the result of step one are defined in terms of utility analysis as the target criteria weightings. They will be used in step three to calculate the final utility values.

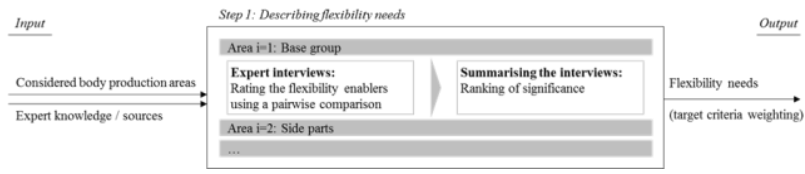

Figure 5. Methodology step 1: evaluating flexibility needs via pairwise comparison

The second step of the methodology aims to identify the flexibility offers of the specific flexible approaches. In terms of utility analysis, the set of complex trading alternatives is described and classified in the second step. For every available approach $\mathrm{j}$, a triangular approach of data collection is used to determine the approaches' flexibility potential for a specific criterion $\mathrm{k}$ as it is shown in figure 6. A rating of 1 expresses that this approach offers a minimum flexibility potential regarding criterion $\mathrm{k}$, whilst a rating of 5 implies that this approach offers a maximum flexibility potential regarding the specific criterion.

The triangular approach of data collection applied in this paper consists of three sources of knowledge. First of all, industry experts with a profound knowledge for the particular approach should be involved when determining the rating. Furthermore, scientific publications, the included concepts and study outcomes should be taken as a reference to judge the flexibility potential of an approach. Internal sources of the respective company can also contribute to determine a representative rating. If the possibility exists, it might also be reasonable to assess strategies of other companies to get an insight in external flexibilization strategies that could be taken as a reference.

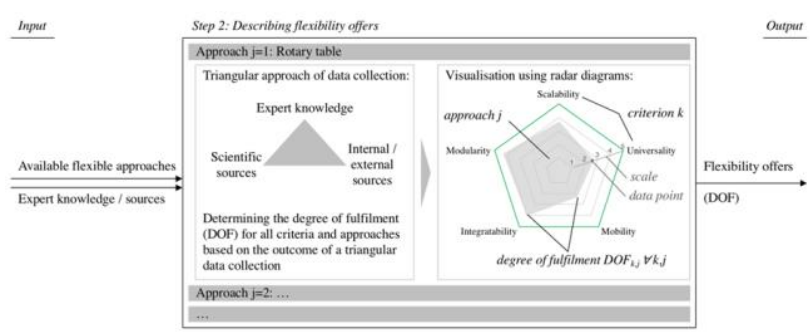

Figure 6. Methodology step 2: evaluating flexibility offers

Based on the data collection, the degree of fulfilment (DOF) per approach $\mathrm{j}$ and criterion $\mathrm{k}$ is defined, resulting in $\mathrm{j}$ times $\mathrm{k}$ DOF values. The five DOF values per approach are visualized using a radar diagram. This design principle represents different alternatives on the basis of previously defined target criteria to enable a quick comparison of the alternatives. Due to the five considered target criteria scalability, universality, mobility, integratability and modularity, this radar diagram comprises five dimensions. The green border of the net represents the optimum fulfilment level of five points. The resulting surface area (marked in grey) enables a quick statement regarding the overall flexibility potential of the considered flexible approach: observing a large surface area implies a large flexibility potential of the approach.

Based on the results of the previous steps, the third step finally matches the flexibility offers and the flexibility needs to determine a ranking of the different approaches $\mathrm{j}$ for each area $\mathrm{i}$. In terms of utility analysis, step three is the actual analysis of the elements (approaches) regarding the target system (weighted target criteria). In a first part of step three, the utility value for every area-/approach-combination is calculated as shown in figure 7. Multiplying the target criteria weightings (step one) by the degree of fulfilment values (step two) results in the partial utility values, the sum of which gives the total utility value UV of the area-/approachcombination. This analysis is also visualized using radar diagrams. Introducing a second scale to the radar diagram enables plotting the target criteria weighting in the same diagram as the degree of fulfilment values. The resulting polygon (marked in blue) represents the flexibility need 
of the specific area. Using this visualization, it is easily observable if the flexibility needs of the analyzed area match the flexibility offers of a specific approach. The case of a perfect match would require the geometries of both surfaces to be exactly the same. Setting the scale of the target criteria weighting to a suitable measure, both surfaces would also consist of the same size in the case of a perfect match.

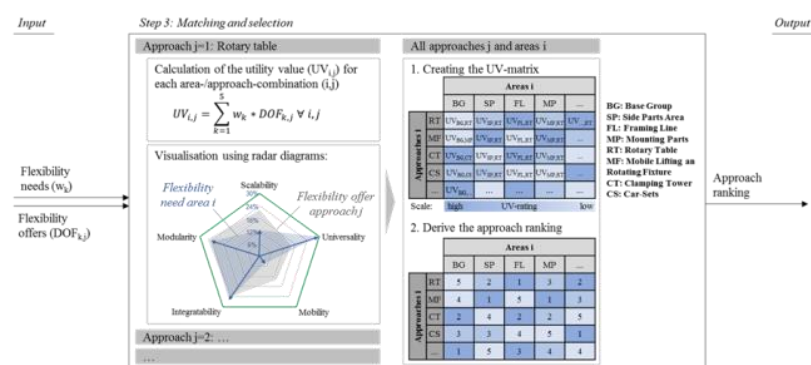

Figure 7. Methodology step 3: matching flexibility needs and offers

Based on the calculated utility values, a UV-matrix is created, displaying all utility values for each area/approach-combination. Using this matrix, we can now introduce a colour scale per column to identify which combinations have higher and lower utility values. A ranking of the different approaches is now easily observable. Looking at the fictive example shown in figure 7, the side parts area (SP) should focus on approaches MF and RT, because they offer the highest utility value rating.

The derived ranking might now be used as the basis for body shop planners to identify for a specific area in which approaches to further invest and which to neglect.

\subsection{Implementation}

Six exemplary flexible approaches from the automotive industry and other branches of industry were selected to be analyzed in this study. Their flexibility potential for an automobile body shop was evaluated using the presented methodology.

Rotary tables to manufacture electrical components are used to ensure a high accuracy and repeatability of the production process. Variant-specific fixtures are mounted on the outer side of the rotary table whilst different machining stations are grouped around the table. This structure enables a production of different component variants using only one set of operating equipment.

Mobile lifting and rotating fixtures are used in a flexible production system for customer-dedicated utility vehicles. The fixtures can be adjusted individually to every vehicle size and configuration. Universally usable and rotatable load attachment devices enable the fixtures to carry dedicated component adapters for every configuration.

Clamping towers for machine tools are used in a company that produces highly customer-dedicated filling lines for fluids. A fast delivery of according machine spare parts is required. To ensure this, the clamping towers offer a four-side accessibility, while each side is equipped with vertically arranged modular clamping devices, that can be changed and integrated easily due to a plug and produce principle.

In order to provide a space-saving component feeding system when delivering attachment parts to an assembly line, car sets are implemented on an automobile manufacturing site. Once they are equipped with the respective components, they follow the production line and enable quick loading and unloading of the carrier sets. Based on a universal design, they can carry different component variants.

The conveyor technology in automobile body shops is often characterized by rigidly linked elements, heavily reducing the potential for flexible production structures. A flexible conveyor technology has been developed to address this problem using modular shuttle elements to carry the components.

Automotive suppliers often produce similar but not equal components for different carmakers. Flexible grippers allow them to replace brand- and productspecific grippers and therefore to reduce set-up times and storage facilities. The flexibility potential in terms of the five flexibility enablers of the approaches driven by their respective characteristics will be shown later in figure 9 . Having defined these six approaches to be considered in this study, seven manufacturing areas of the considered automobile body shop (base group, side parts, framing line, mounting parts, small part center, conveyor technology and in-line logistics) were defined to be analyzed, if an implementation of the approaches might be a promising flexible concept for these areas.

In the first step of the methodology, the target criteria weightings were derived from interviews with experts of each area using the pairwise comparison method. An average result summing up all the areas is provided in figure 8 . This implies that universality $(31 \%)$ is on average the most important characteristic for increasing flexibility in body production, particularly increasing the required product flexibility. Integratability $(26 \%)$ and modularity $(25 \%)$ are also essential flexibility enabling features, which are also mainly addressing the product flexibility. Less important are scalability (13\%) and mobility $(5 \%)$, which are mainly focused on adjusting the production flexibility.

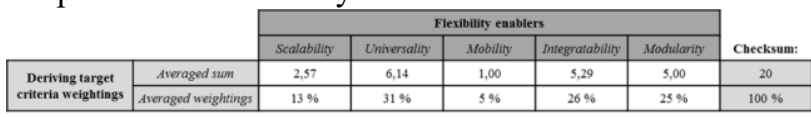

Figure 8. Results of step one - average values of the seven considered areas

Analysing the above described approaches with the second step of the methodology has generated the radar diagrams shown in figure 9. It is observable that the different approaches generally have strengths and weaknesses in different areas, which strengthens the thesis that not every approach is suitable for all examined areas. Comparing the shown surface areas, it is also observable that some approaches (e.g. the flexible conveyor technology) provide a high potential for flexibilization in every criterion whilst other approaches offer a significantly lower potential (e.g. the car-sets). 
To focus on the main outcome of this implementation chapter, the results of step three are shown in figure 10 as a simplified UV-matrix, which is the summary of the calculations done as described in figure 7. Approaches with a high utility value are marked as preferred and will be further investigated by the company's body shop areas as a follow-up to this study. This will comprise a detailed analysis of each approach, if and how it fits into the existing production system of the area and planning for future production systems.

Non-preferred approaches will not be further investigated at this time, but enhancements of the underlying technologies will be followed up and - if appropriate - the according flexibility ratings will be adjusted to the actual state of the art.

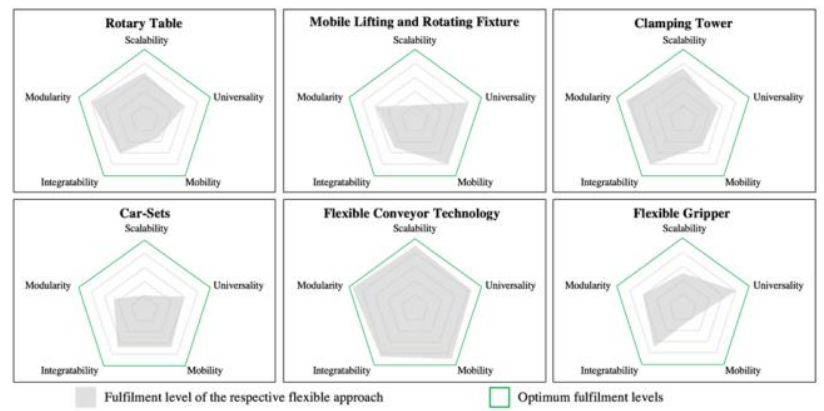

Figure 9. Results from the methodology step 2

When considering the results shown in figure 10 , it seems advisable from a company perspective to firstly focus on the approaches that are preferable for many areas and therefore offer cross-areal benefits when it comes to research and development efforts but also implementation costs at a later time.

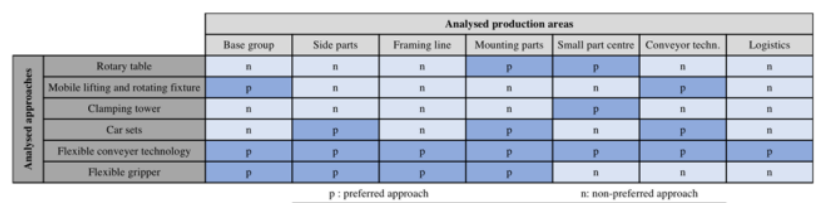

Figure 10. Assignment of specific flexible approaches to suitable car body production areas.

\section{Conclusion and Future Work}

Today, the automotive industries and particularly the inflexible automobile body production are facing the challenge to react to market fluctuations and individualization wishes of customers in a flexible manner. It is therefore important to consider approaches and concepts to enhance the flexibility of automobile production systems. A literature review has shown that there is a variety of approaches already existing in theoretical publications and industry projects. It has also been identified that there is currently no mechanism available to identify which approaches to consider when planning to increase the flexibility of industry production systems. Therefore, the presented methodology was developed and implemented to enable a quantitative ranking of flexible approaches for each body production area based on expert knowledge and several further sources of information.

The study has shown that different body shop areas have different preferences regarding the significance of the five considered flexibility enablers that were taken as the set of target criteria for the methodology, whilst available approaches offer different sets of flexibility potentials. This implies that the dedicated flexibility needs of each area and the flexibility offers of each approach need to be taken into account when selecting flexible approaches for specific areas. The presented methodology satisfies this need for matching flexibility needs and offers.

Future investigations should also take into account the time scale when considering the flexible potential of approaches in terms of flexibility offers, as some concepts develop very fast over time and might become more promising in the near future. It should also be considered, that flexibility needs might also be subject to changing preferences of the areas over time, when trying to meet the changing requirements caused by upcoming further market trends.

To increase the value of the methodology, a further objective for future work is to abstract the approaches to a more general level, so that the results of the methodology are not only applicable to certain use casespecific approaches but also to general classes of flexible approaches.

\section{References}

1. Schuh, G., Riesener, M., 2018. Produktkomplexität managen. Carl Hanser Verlag München.

2. Steegmüller, D., Zürn, M., 2017: Wandlungsfähige Produktionssysteme für den Automobilbau der Zukunft; In: Vogel-Heuser et al.; Handbuch Industrie 4.0 B.1. Springer-Verlag GmbH D.

3. Onlinequelle 2018 (https://www.finanzen.net/nachricht/aktien/blumeim-interview-porsche-chef-versteht-eigenebatterieproduktion-als-kernkompetenz-5108593), Zugriff: 24.09.2018.

4. Kamkper, A., 2013. Elektromobilität. Springer Viewig Verlag Berlin.

5. Wemhöner, N., 2006. Flexibilitätsoptimierung zur Auslastungssteigerung im Automobilrohbau. Shaker Verlag GmbH Aachen.

6. Keller, C., Putz, M., 2016. Force-controlled adjustment of car body fixtures - verification and performance of the new approach. Procedia CIRP.

7. Bergweiler, G., 2018. Flexible Body Shop for EMobility. Automotive Circle Conference Bad Nauheim (Conference presentation).

8. Hernández Morales, R., 2003. Systematik der Wandlungsfähigkeit. VDI-Verlag Düsseldorf.

9. Hansen, J. O., Kampker, A., Triebs, J., 2018. Methodology for flexibility in the future automobile body shop: results of a comprehensive crossindustry study. 51st CIRP Conference on MS. 
10. Wiendahl, H.-P., 2002. Wandlungsfähigkeit: Schlüsselbegriff der zukunftsfähigen Fabrik. wt Werkstatttechnik online (2002/4).

11. Kampker, A., Bichler, M., Triebs, J., Böhm, T., 2018. Challenges for car body shops of electric sports cars. 18. International Stuttgart Symposium. Springer Fachmedien GmbH Wiesbaden.

12. Lambertz, A., 2010. Technisch-wirtschaftliche Bewertung von Flexibilität in Rohbaunebenlinien. Fraunhofer Verlag Stuttgart.

13. Sethi, A. K., Sethi, S. P., 1990. Flexibility in Manufacturing: A Survey. The International Journal of Flexible Manufacturing Systems, Nr.2. Kluwer Academic Publishers Boston.

14. Wiendahl, H.-P., Reichardt J., Nyhuis, P., (2014). Handbuch Fabrikplanung. Konzept, Gestaltung und Umsetzung wandlungsfähiger Produktionsstätten (2. Auflage). Carl Hanser Verlag.

15. Schuh, G., Gulden, A., Wemhöner, N., Kampker, A., 2004. Bewertung der Flexibilität von Produktionssystemen - Kennzahlen zur Bewertung der Stückzahl-, Varianten- und Produktänderungsflexibilität auf Linienebene. wt Werkstatttechnik online (2004/6).
16. Kampker, A., Bergweiler, G., Hansen, J. O., Borbola, W. J., 2017. Vorrichtungsloses Laserschweißen im Karosseriebau. ATZ 02/2017.

17. Schlather, F., Oefele, F., Zaeh, M. F., 2016. Toward a feature-based approach for fixtureless build-up of sheet metal structures. Int. J. of Engineering and Techn. Research, V. 5, Issue-4.

18. Webster, S. A., 2015. Flexible Manufacturing for a Future with Mixed Materials. AdvancedManufacturing.org.

19. KUKA Systems GmbH. Industrie 4.0_Matrix production. www.kuka.com (brochure).

20. Lafou, M., Mathieu, L., Pois, S., Alochet, M., 2016. Manufacturing System Flexibility: Product Flexibility Assessment. 41st CIRP Conference on Manufacturing Systems.

21. Lanza, G., Rühl, J., Peters, S., 2009. Bewertung von Stückzahl- und Variantenflexibilität in der Produktion. ZWF Jahrgang 104 (2009) 11.

22. Rogalski, S., 2009. Entwicklung einer Methodik zur Flexibilitätsbewertung von Produktionssystemen. Universitätsverlag Karlsruhe) 